\title{
Review of ectopic pregnancy at tertiary care center: 2 years analysis
}

\author{
Suman S. Sharma*, Ashish V. Gokhale, Shonali Agarwal, Dimpi Modi, Kajal Gedia
}

Department of Obstetrics and Gynaecology, Baroda Medical College, Gujarat, India

Received: 01 July 2020

Revised: 21 August 2020

Accepted: 03 September 2020

\section{*Correspondence:}

Dr. Suman S. Sharma,

E-mail: Sharmasuman29@gmail.com

Copyright: (c) the author(s), publisher and licensee Medip Academy. This is an open-access article distributed under the terms of the Creative Commons Attribution Non-Commercial License, which permits unrestricted non-commercial use, distribution, and reproduction in any medium, provided the original work is properly cited.

\section{ABSTRACT}

Background: Ectopic pregnancy is defined as any intra or extra-uterine pregnancy in which the fertilized ovum implants at an aberrant site which is inconducive to its growth and development. It is a catastrophic and life-threatening condition and one of the commonest acute abdominal emergencies affecting approximately $2 \%$ of all pregnancies. The purpose of this study is to review cases of ectopic pregnancy and determine: incidence, high risk factors, types of clinical presentation, diagnostic methods, management, morbidity and mortality.

Methods: The present study, conducted over a period of 2-year, total number of deliveries was 16,144 and total number of ectopic pregnancies was 116 . More than half of the cases $(56.04 \%)$ had one or the other identifiable risk factor. Results: Amongst the various risk factors studied, history of previous pelvic surgery (15.43\%), history of Pelvic inflammatory disease (PID) (12.9\%), use of Intrauterine contraceptive device (IUCD) (10.3\%) and either spontaneous or induced abortion $(7.76 \%$ ) has been found. History of self-administered medical termination of pregnancy (MTP) pill was present in $3.45 \%$. Repeat ectopic pregnancies were seen in $1.72 \%$. There was no identifiable risk factor in $49.63 \%$ of cases.

Conclusion: Ectopic pregnancy is a major challenge in obstetrical practice because of its varied clinical presentation. It can be diagnosed early by keeping a high index of suspicion. Undue delay in referral reduces significant morbidity and improves the chances of preserving future fertility. Mass education regarding safe abortion practices and post abortal care should be promoted. Unsupervised usage of MTP pill intake should be condemned.

Keywords: Ectopic, Medical management, Risk factors, Tubal disease

\section{INTRODUCTION}

An ectopic, or extra-uterine pregnancy is defined as a pregnancy implanted outside of the uterine cavity with over $98 \%$ implanting in the fallopian tube. ${ }^{1,2}$ The most common site of ectopic pregnancy is fallopian tube followed by ovary and abdomen. Some ectopic pregnancies resolve spontaneously, but others continue to grow and lead to rupture of the tube. ${ }^{3}$ It accounts for $2 \%$ of first trimester pregnancies of them $98 \%$ are in various part of the fallopian tube and out of these, $70 \%$ are in the ampullary region, $12 \%$ isthmic, $11.1 \%$ fimbrial, $3.2 \%$ ovarian, $2.4 \%$ interstitial, and $1.3 \%$ in the abdominal cavity. ${ }^{4,5}$ It is a catastrophic and life threatening condition and one of the commonest acute abdominal emergencies.

Diagnosis requires a high index of suspicion as the classic triad of amenorrhea, abdominal pain and vaginal bleeding is not seen in majority of cases. The clinical presentation seems to be varied and women may present with nonspecific symptoms, unaware of an on-going pregnancy or even present with hemodynamic shock. Risks are higher in women with damage to the fallopian tubes due to pelvic infections, surgery, or previous ectopic pregnancy. The early diagnosis of this condition over the past two decades has allowed a definitive medical management of unruptured ectopic pregnancy with successful outcomes. 
Treatment of diagnosed ectopic pregnancy includes medical management with intramuscular methotrexate, surgical management via salpingostomy or salpingectomy, and, in rare cases, expectant management.

The purpose of this study was to review all cases of ectopic pregnancy and determine: incidence, high risk factors, types of clinical presentation, diagnostic methods, treatment modalities, morbidity and mortality.

\section{METHODS}

\section{Type of study}

The study was retrospective.

\section{Sample size}

116 patients who had ectopic pregnancy were included.

\section{Study setting}

The study was conducted at SSG Hospital, Baroda, Gujarat, India.

\section{Study duration}

The present study was conducted for a period of 2 years from January 2018 to December 2019.

\section{Methodology}

The data was collected from medical record room. A meticulous analysis was done to get information regarding the demographic data, parity, risk factors, clinical features, mode of management and need for blood transfusion was noted.

\section{Inclusion criteria}

All women with confirmed ectopic pregnancies.

\section{Statistical anlaysis}

Data was entered in Microsoft Excel spread sheet and analyzed using Statistical package for the social sciences (SPSS) software version 19.0. For categorical variables, data was compiled as frequency and percentage. The data was represented in form of tables and charts.

\section{RESULTS}

As per table 1, it was found that the majority of ectopic pregnancies occurred in the females between age group 26-30 years (42.24\%). This was followed by age group of $20-25$ years $(39.66 \%)$. In this scenario, it can be assumed that younger age group is vulnerable because of early marriage.
Table 1: Distribution of cases according to age.

\begin{tabular}{|lll|}
\hline Age & No. of cases & Percentage \\
\hline $\mathbf{2 0}$ & 1 & 0.86 \\
\hline $\mathbf{2 0 - 2 5}$ & 46 & 39.66 \\
\hline $\mathbf{2 6 - 3 0}$ & 49 & 42.24 \\
\hline $\mathbf{3 0}$ & 20 & 17.24 \\
\hline Total & 116 & 100.00 \\
\hline
\end{tabular}

According to table 2, gravida 2, 3 accounted for the maximum number of cases $(65.51 \%)$. A trend is seen where multigravidas are involved more in ectopic cases. The primigravida patients account for $20.69 \%$ and it can be due to unknown risk factor.

Table 2: Distribution of cases according to birth order.

\begin{tabular}{|lll|}
\hline Gravida & No. of cases & Percentage \\
\hline $\mathbf{1}$ & 24 & 20.69 \\
\hline $\mathbf{2}$ & 36 & 31.03 \\
\hline $\mathbf{3}$ & 40 & 34.48 \\
\hline$>=\mathbf{4}$ & 16 & 13.79 \\
\hline Total & 116 & 100.00 \\
\hline
\end{tabular}

According to table 3 , the most common presentation documented was pain in abdomen, followed by amenorrhea $(21.55 \%)$ and bleeding per vagina $(20.69 \%)$ and triad of ectopic was seen in $21.2 \%$ patients. Most of the patients did not have major symptoms, shock was seen in $12.93 \%$, followed by vomiting in $6 \%$. Therefore, it is required that every women of reproductive age who complains of abdominal pain must undergo pregnancy test.

Table 3: Distribution according to presentation.

\begin{tabular}{|lll|}
\hline Presentation & No. of cases & Percentage \\
\hline Amenorrhea & 25 & 21.55 \\
\hline Bleeding per vagina & 24 & 20.69 \\
\hline Pain in abdomen & 45 & 38.79 \\
\hline Shock & 15 & 12.93 \\
\hline Vomiting & 7 & 6.03 \\
\hline Total & 116 & 100.00 \\
\hline
\end{tabular}

Table 4 depicts that the most common site of ectopic was tubal (ampulla>isthmus $>$ fimbria) as seen in most of the studies. The tubal site is known to be the most common site, but due to increase in pregnancy rates, there has also been cases of Lower segment caesarean section (LSCS) scar site pregnancy which accounted to be $1.72 \%$.

As per table 5, ectopic pregnancy seems to be more in patients having risk factors. More than half of the cases $(56.04 \%)$ had one or the other identifiable risk factor. Risk factors play a very important role in pathogenesis. The most important being Pelvic inflammatory disease (PID), tubal surgery, so the patients with risk factors are educated about the possibility of ectopic pregnancy. 
Table 4: Distribution according to site.

\begin{tabular}{|lll|}
\hline Site & No. of cases & Percentage \\
\hline Ampulla & 73 & 62 \\
\hline Isthmus & 25 & 21.55 \\
\hline Fimbria & 13 & 10.34 \\
\hline Interstitial & 03 & 2.59 \\
\hline LSCS Scar site & 02 & 1.72 \\
\hline Total & 116 & 100.00 \\
\hline
\end{tabular}

Table 5: Distribution according to risk factors.

\begin{tabular}{|lll|}
\hline Risk factors & No. of cases & Percentage \\
\hline $\begin{array}{l}\text { No identifiable risk } \\
\text { factor }\end{array}$ & 51 & 43.96 \\
\hline IUCD & 12 & 10.34 \\
\hline PID & 15 & 12.93 \\
\hline Pelvic surgery & 11 & 9.4 \\
\hline Previous abortion & 09 & 7.76 \\
\hline Tubectomy & 07 & 6.03 \\
\hline Ovulation induction & 07 & 6.03 \\
\hline MTP pill & 04 & 3.45 \\
\hline Previous ectopic & 02 & 1.72 \\
\hline Total & 116 & 100.00 \\
\hline
\end{tabular}

As per table 6, most patients were operated by open salpingectomy (77 patients) followed by laparoscopic salpingectomy (27 patients). The more cases of open salpingectomy is mainly because of rupture and hemoperitoneum, because being a tertiary care centre, referral cases add up to be the major bulk of cases.

Table 6: Distribution of cases according to type of surgery done.

\begin{tabular}{|lll|}
\hline Procedure & No. of cases & Percentage \\
\hline Open salpingectomy & 77 & 66.37 \\
\hline $\begin{array}{l}\text { Laparoscopic } \\
\text { salpingectomy }\end{array}$ & 27 & 23.28 \\
\hline Milking & 06 & 5.17 \\
\hline Medical treatment & 04 & 3.45 \\
\hline $\begin{array}{l}\text { Open excision and } \\
\text { repair }\end{array}$ & 02 & 1.72 \\
\hline Total & 116 & 100.00 \\
\hline
\end{tabular}

Table 7: Distribution of cases according to no. of blood transfusion.

\begin{tabular}{|lll|}
\hline Blood transfusion & No. of cases & Percentage \\
\hline $\mathbf{1}$ & 44 & 37.93 \\
\hline $\mathbf{2}$ & 31 & 26.72 \\
\hline $\mathbf{3}$ & 12 & 10.34 \\
\hline No blood & 29 & 25.00 \\
\hline Total & 116 & 100.00 \\
\hline
\end{tabular}

Patients presented with hypovolemic shock required blood transfusions according to the blood loss and hemodynamic status. The early and most important management of hypovolemia is replacement of blood, it also acts as a preventive measure to prevent further life-threatening complication like Disseminated intravascular coagulation (DIC).

\section{DISCUSSION}

The incidence of ectopic pregnancy has been on the rise over the past decades. It has now become one of the most common and most serious events leading to maternal death in the first trimester. It has been seen to complicate 0.25 $2.0 \%$ of all pregnancies worldwide. ${ }^{5}$

In present study the incidence was $1.18 \%$, comparable to other studies in developing countries, where it ranges from $0.56-1.5 \%$.

Predominance of young age women can be attributed to fact that women in India encounter early marriage and reproduction. The same result can be seen in this study as it was found that the majority of ectopic pregnancies, occurred in the females between age group 26-30 years (42.24\%) which is comparable to $(40.81 \%)$ in $28-32$ year age group in the study by Sharma R, et al. ${ }^{6}$

Multigravida women were found to be most common (79.3\%) among all the ectopic cases and this was comparable to the study done by K. Swathi et al where multipara women were $84 \% .^{7}$

In this study, it was found that the most common presentation documented was pain in abdomen, followed by amenorrhea $(21.55 \%)$ and bleeding per vagina $(20.69 \%)$ and triad of ectopic was seen in $21.2 \%$ patients. The clinical presentation among ectopic patients are varied, ranging from complain of amenorrhea to shock and hemodynamic instability.

The most common site of ectopic was tubal (ampulla $>$ isthmus $>$ fimbrial) as seen in the study by Bouyer. ${ }^{8}$

Risk factors are very important in an ectopic pregnancy as, more than half of the cases $(56.04 \%)$ had one or the other identifiable risk factor. As per study done by Swati K et al, $80 \%$ of the patients had identifiable risk factors, of which past history of PID in $26 \%$, history of previous abortion in $16 \%$, infertility in $10 \%$, uterine anomalies in $4 \%$, history of previous ectopic pregnancy in $6 \%$, usage of Intrauterine contraceptive devices (IUCD) and oral contraceptive pills (OCP) in $6 \%$ each and tubectomy in $6 \%$ were noted. ${ }^{7}$ The results conclude that the aetiology of ectopic pregnancy seems to be involving tubal factor involvement, either by infection or by previous surgical procedures.

In majority of cases $(66.37 \%)$ open salpingectomy by laparotomy was done because of poor general condition 
and hemodynamic instability. In study done by Pratibha V et al, milking was done in $2.33 \%$ cases while in present study it was $5.17 \%$, and partial salpingectomy was done in $13.25 \%$ case. ${ }^{9}$ Total salpingectomy was done by them in majority of case $(66.3 \%)$, which was same as present study $(66.37 \%)$.

The hemodynamic instability cause by hemoperitoneum was managed effectively by replacement of blood products and ventilatory support which resulted in zero mortality in this study. Blood transfusion was required in $75 \%$ cases which is comparable to study by Divyesh $\mathrm{P}$ where transfuions were required in $65.5 \% .^{10}$

Over the counter availability of Medical termination of pregnancy (MTP) kit has resulted in bypassing of Ultrasonography (USG) for detection of pregnancy and leads to increase in cases of ruptured ectopic.

Due to lack of awareness and education in the rural community, 1st trimester scan is missed leading to failure of early detection.

The incidence in a tertiary care centre is assumed to be on a higher side as influx of referred patients for ruptured ectopic pregnancy constitutes a substantial part.

\section{CONCLUSION}

Ectopic pregnancy is still a major challenge in obstetrical practice because of its varied clinical presentation and being a common cause of 1 st trimester mortality. Undue delay in referral reduces significant morbidity and improves the chances of preserving future fertility. Mass education regarding safe abortion practices and post abortal care should be promoted. Unsupervised usage of MTP pill intake should be condemned. In conclusion, identifying underlying risk factors, availability of ultrasound, with availability of beta human chorionic gonadotropin (hCG) assay and timely intervention will help reduce the morbidity and mortality.

\section{ACKNOWLEDGMENTS}

We would like to thank all our seniors, juniors, colleagues, staff who have helped me to accomplish the study.
Funding: No funding sources

Conflict of interest: None declared

Ethical approval: The study was approved by the Institutional Ethics Committee

\section{REFERENCES}

1. Walker JJ. Ectopic pregnancy. Clinical Obstetrics Gynecology. 2007;50(1):89-99.

2. Varma, R., and Gupta, J. Tubal ectopic pregnancy. BMJ clinical evidence. 2012;2012:1406.

3. Varma R, Gupta J. Tubal ectopic pregnancy. BMJ Clinical Evidence. 2009;2009:1406.

4. Strandell A, Thorburn J, and Hamberger, L. Risk factors for ectopic pregnancy in assisted reproduction. Fertility and sterility. 1999;71(2),282-286.

5. Perlman B E, Guerrero K, Karsalia R, and Heller DS. Reproductive outcomes following a ruptured ectopic pregnancy. The European Journal of Contraception \& Reproductive Health Care. 2020;25(3):.206-208.

6. Sharma R, Biligi DS. A study of histopathological changes in fallopian tubes in ectopic pregnancy. International Journal of Current Research and Review. 2015;7(16):54.

7. Prasanna B, Jhansi CB, Swathi K, Shaik MV. A study on risk factors and clinical presentation of ectopic pregnancy in women attending a tertiary care centre. IAIM. 2016;3(1):90-6.

8. Bouyer J, Saurel-Cubizolles MJ, Grenier C, Aussel L, and Job-Spira N. Ectopic pregnancy and occupational exposure of hospital personnel. Scandinavian journal of work, environment \& health. 1998;24(2):98-103.

9. Vyas PS and Vaidya P. Epidemiology, Diagnosis and Management of Ectopic pregnancy. Research Articles. 1998;1-11.

10. Panchal DD, Vaishnav DG, Solanki DK. Study of Management in Patient with Ectopic Pregnancy. National Journal of Integrated Research in Medicine. 2011;2(3);2:3.

Cite this article as: Sharma SS, Gokhale AV, Agarwal S, Modi D, Gedia K. Review of ectopic pregnancy at tertiary care center: 2 years analysis. Int J Reprod Contracept Obstet Gynecol 2020;9:4036-9. 